\title{
Robotic total endoscopic double-vessel coronary artery bypass grafting-state of procedure development
}

\author{
Johannes Bonatti, MD, FETCS, ${ }^{a}$ Eric J. Lehr, MD, PhD, FRCSC, ${ }^{\text {a }}$ Thomas Schachner, MD, ${ }^{b}$ \\ Dominik Wiedemann, MD, ${ }^{\mathrm{b}}$ Felix Weidinger, MD, ${ }^{\mathrm{b}}$ Brody Wehman, MD, ${ }^{\mathrm{a}}$ Andreas R. de Biasi, MD, ${ }^{\mathrm{a}}$ \\ Nikolaos Bonaros, MD, PhD, FETCS, ${ }^{\mathrm{b}}$ and Bartley Griffith, $\mathrm{MD}^{\mathrm{a}}$
}

\begin{abstract}
Objective: Robotic total endoscopic coronary artery bypass grafting (TECAB) has been under development for 10 years. With increasing experience and technological improvement, double-vessel TECAB has become feasible. The aim of the present study was to compare the current outcomes of single- and double-vessel TECAB.

Methods: Between 2001 and 2011, 484 patients underwent TECAB by 4 surgeons at 2 institutions. The median patient age was 60 years (range, 31-90), and the median European System for Cardiac Operative Risk Evaluation was 2 (range, $0-13)$. Single-vessel $(n=334)$ and double-vessel $(n=150)$ procedures were performed using the da Vinci, da Vinci S, and da Vinci Si robotic systems.

Results: Compared with the single-vessel procedure, double-vessel TECAB required a longer operative time (median, 375 minutes; range, 168-795; vs median, 240; range, 112-605; $P<.001$ ) and had an increased conversion rate to a larger thoracic incision $(31 / 150[20.7 \%]$ vs $31 / 334[9.3 \%] ; P<.001)$. The median ventilation time was 10 hours (range, 0-288) for double-vessel versus 8 hours (range, 0-278) for single-vessel procedures $(P=.006)$. The hospital stay was comparable, with 6 days (range, 2-27) for double-vessel TECAB and 6 days (range, $2-33)$ for single-vessel TECAB $(P=.794)$. Perioperative mortality was $0.3 \%(1 / 334)$ with single-vessel TECAB and 2.0\% (3/150) with double-vessel TECAB $(P=.090)$. Freedom from major adverse cardiac and cerebral events at 5 years was similar after double- and single-vessel TECAB $(73.5 \%$ vs $83.1 \%$, $P=.150)$. The 5-year survival was $95.8 \%$ and $93.9 \%(P=.708)$.
\end{abstract}

Conclusions: Double-vessel TECAB appears feasible and reproducible. The operative times were longer and the conversion rates to a larger thoracic incision were greater than with single-vessel TECAB. Also, the postoperative ventilation time was longer. Other perioperative morbidity and mortality and the recovery time and long-term clinical outcomes, however, were comparable. (J Thorac Cardiovasc Surg 2012;144:1061-6)

Double-vessel total endoscopic coronary artery bypass grafting (TECAB) represents a second generation of closed-chest coronary bypass grafting procedures. With application of robotic technology, the procedures are performed using ports, without the need for thoracotomy. After an initial phase in which only single-vessel coronary artery bypass grafting procedures were performed using robotics, some groups reported successful first case reports of double-vessel TECAB. ${ }^{1,2} \mathrm{~A}$ first small series was published by our group in $2007 .^{3}$ To date, little information is available on the intraoperative performance, perioperative

From University of Maryland School of Medicine, ${ }^{\mathrm{a}}$ Baltimore, Md; and Innsbruck Medical University, ${ }^{\mathrm{b}}$ Innsbruck, Austria.

Disclosures: Authors have nothing to disclose with regard to commercial support.

Read at the 92nd Annual Meeting of The American Association for Thoracic Surgery, San Francisco, California, April 28-May 2, 2012.

Received for publication May 15, 2012; revisions received July 28, 2012; accepted for publication Aug 3, 2012.

Address for reprints: Johannes Bonatti, MD, FETCS, Division of Cardiac Surgery, Department of Surgery, University of Maryland School of Medicine, 22 South Greene St, N4W94, Baltimore, MD 21201 (E-mail: johannesbonatti@gmail.com). $0022-5223 / \$ 36.00$

Copyright (c) 2012 by The American Association for Thoracic Surgery

http://dx.doi.org/10.1016/j.jtcvs.2012.08.023 results, and long-term outcomes of double-vessel TECAB. $\mathrm{We}$, therefore, analyzed a series of 150 double-vessel TECABs and compared these with a series of single-vessel TECABs performed during the same study period.

\section{METHODS}

From 2001 to 2011, 334 single-vessel and 150 double-vessel TECAB procedures were performed using the da Vinci, da Vinci S, and da Vinci Si robotic systems (Intuitive Surgical, Inc, Sunnyvale, Calif). The operations were performed at the Innsbruck Medical University and the University of Maryland Medical Center by 4 console surgeons (J.B., T.S., N.B., and E.L.). The demographic data for the whole study population are listed in Table 1, and the procedures performed are listed in Table 2.

\section{General Surgical Technique}

All operations were performed with the patients under general anesthesia with double-lumen tube intubation. The patients were placed in the supine position with the left or right chest slightly elevated. Percutaneous defibrillator patches were placed preoperatively.

Ports were placed under ipsilateral lung collapse. A camera port was inserted into the left fifth intercostal space, and instrument ports were inserted into the third and seventh intercostal spaces. Assistance ports were created in the subcostal region for the EndoWrist (Intuitive Surgical, Inc) endostabilizer and in the parasternal region for transthoracic assistance. The internal thoracic artery (ITA) was harvested using a pedicled technique during the early phase of our series and was skeletonized during the later 


\section{Abbreviations and Acronyms}

$\mathrm{CABG}=$ coronary artery bypass grafting

ITA $=$ internal thoracic artery

$\mathrm{TECAB}=$ total endoscopic coronary artery bypass grafting

phases. For revascularization of the right coronary artery territory ports were placed on the right side of the chest, mirroring the left-sided port placements. During the very last phase of our experience, the right coronary artery system was also approached from the patient's left side. For exposure of the lateral and back walls of the heart, the endoscopic stabilizer was used. All anastomoses were created using a short, double-armed 7-0 polypropylene suture.

The arrested heart technique for TECAB has been previously described, and videos of this procedure are available on OR-LIVE.com (available from: http://www.orlive.com/umm/videos/tecab-totally-endoscopic-coro nary-artery-bypass) and the Minimally Invasive Robotic Association Web site (available from: http://www.miraweb.org/video.htm). ${ }^{4}$ The procedures were performed using remote-access heart-lung machine perfusion and ascending aorta balloon occlusion for cardioplegia. For creation of bypass grafts on the beating heart, a suction stabilizer was used, as described previously. ${ }^{5}$ The target vessel was encircled with Silastic tapes, and shunts were used during the later phase of our series. Also during the later phase, patients were cannulated prophylactically, and the heart-lung machine was used in cases of significant space constraints, for exposure of the back wall of the heart, or in the case of hemodynamic instability. We described this cannulation technique in $2009 .^{6}$

TABLE 1. Demographic data

\begin{tabular}{lccc}
\hline \multicolumn{1}{c}{ Variable } & $\begin{array}{c}\text { Single-vessel } \\
\text { TECAB }\end{array}$ & $\begin{array}{c}\text { Double-vessel } \\
\text { TECAB }\end{array}$ & $\begin{array}{c}\boldsymbol{P} \\
\text { value }\end{array}$ \\
\hline Patients $(\mathrm{n})$ & 334 & 150 & \\
Age $(\mathrm{y})$ & $60(31-90)$ & $61(38-83)$ & .178 \\
Men & $233(69.8 \%)$ & $117(78.0 \%)$ & \\
Women & $101(31.2 \%)$ & $33(22.0 \%)$ & .150 \\
Height $(\mathrm{cm})$ & $172(137-196)$ & $173(142-188)$ & .766 \\
Weight $(\mathrm{kg})$ & $80(48-158)$ & $80(41-180)$ & .393 \\
BMI $\left(\mathrm{kg} / \mathrm{m}^{2}\right)$ & $27(18-47)$ & $28(14-46)$ & .379 \\
CVI & $23(7.0 \%)$ & $21(14.0 \%)$ & .012 \\
Peripheral vascular disease & $22(6.6 \%)$ & $9(6.0 \%)$ & .492 \\
Dialysis & $8(2.4 \%)$ & $0(0.0 \%)$ & .05 \\
Preoperative creatinine & $0.98(0.56-12.0)$ & $0.94(0.48-2.0)$ & .082 \\
Prophylactic IABP & $14(4.2 \%)$ & $7(4.7 \%)$ & .802 \\
Previous myocardial & $91(27.2 \%)$ & $61(40.7 \%)$ & .002 \\
$\quad$ infarction & & & \\
LVEF $(\%)$ & $60(20-88)$ & $60(25-80)$ & .125 \\
STS risk score $(\%)$ & $0.59(0.18-0.99)$ & $0.57(0.18-0.62)$ & .448 \\
EuroSCORE & & & .136 \\
$\quad$ Median & 2 & 2 & \\
Range & $0-13$ & $0-7$ & \\
$\quad$ Mean \pm SD & $2.17 \pm 2.24$ & $2.35 \pm 1.94$ & \\
Learning curve cases & $113(33.8 \%)$ & $105(70.0 \%)$ & .001 \\
\hline Da & & & \\
\hline
\end{tabular}

Data presented as $\mathrm{n}(\%)$ or median (range), unless noted otherwise. TECAB, Total endoscopic coronary artery bypass grafting; $B M I$, body mass index; $C V I$, chronic venous insufficiency; $I A B P$, intra-aortic balloon pump; $L V E F$, left ventricular ejection fraction; STS, Society of Thoracic Surgeons; EuroSCORE, European System for Cardiac Operative Risk Evaluation.

\section{Definitions}

The first 20 cases of a new procedure variation for a single surgeon were defined as the learning curve cases and were documented as such. Of the 334 single-vessel TECAB cases and 150 double-vessel TECAB cases, $112(33.5 \%)$ and $105(70.0 \%)$ were a part of a single surgeon's learning curve, respectively $(P<.001)$. The operative time was defined as the interval from skin incision to skin closure. Conversion was defined as the need to open the chest through a larger incision such as sternotomy or thoracotomy because of technical difficulties or inadequate intraoperative revascularization.

\section{Statistical Analysis}

The data were collected prospectively, entered into an institutional review board-approved database, and analyzed using the IBM SPSS, version 19.0 (IBM Corp, Armonk, NY), statistical software package. Continuous variables are presented as medians and ranges and categorical variables as absolute values and percentages. Comparisons between single- and double-vessel TECAB were done using the Mann Whitney- $U$ test for continuous variables and the $\chi^{2}$ test or Fisher exact test for categorical variables, as appropriate. Long-term survival and freedom from adverse events were calculated using the Kaplan-Meier method. For comparison between groups, we used the log-rank test.

\section{RESULTS}

Of all the procedures, 303 of 334 single-vessel TECAB and 119 of 150 double-vessel TECAB were completed total

TABLE 2. Procedures performed

\begin{tabular}{|c|c|c|}
\hline Variable & $\begin{array}{c}\text { Arrested } \\
\text { heart }\end{array}$ & $\begin{array}{c}\text { Beating } \\
\text { heart }\end{array}$ \\
\hline \multicolumn{3}{|l|}{ Single vessel } \\
\hline LITA to LAD & 234 & 75 \\
\hline LITA to Dg & 8 & \\
\hline LITA to OM & 6 & 1 \\
\hline RITA to LAD & 3 & 2 \\
\hline RITA to RCA & 3 & \\
\hline LITA to LAD (from right side) & 1 & \\
\hline RITA to LAD (from right side) & 1 & \\
\hline Total & 256 & 78 \\
\hline \multicolumn{3}{|l|}{ Double vessel } \\
\hline RITA LAD + LITA Dg/OM/Cx & 62 & 14 \\
\hline LITA to LAD/LAD jump & 34 & 3 \\
\hline RITA to LAD, LITA Y-graft to PDA & 5 & \\
\hline LITA to LAD, RITA Y-graft to PDA & 4 & 1 \\
\hline LITA to LAD, RITA to RCA (from right) & 3 & \\
\hline RITA to LAD, LITA Y-graft to RCA (from right) & 5 & \\
\hline LITA to LAD, RITA Y-graft to OM & 2 & \\
\hline LITA to LAD, SVG to RCA (from right) & 3 & \\
\hline LITA to LAD, SVG to Dg & 1 & 2 \\
\hline LITA to LAD, SVG to OM & 1 & 3 \\
\hline LITA to OM/ramus jump & 1 & \\
\hline RITA/RA composite to $\mathrm{Dg} / \mathrm{OM}$ & 1 & \\
\hline LITA to LAD, RITA to Dg & & 3 \\
\hline LITA to LAD/Dg jump & & 2 \\
\hline Total & 122 & 28 \\
\hline
\end{tabular}


endoscopically (Table 3 ). The operative times are also listed in Table 3. The operative times were consistently longer for the completely endoscopic double-vessel TECAB procedures.

The postoperative results are listed in Table 4. In-hospital mortality was $0.3 \%(1 / 334)$ for single-vessel TECAB and $2.0 \%(3 / 150)$ for double-vessel TECAB $(P=.090)$. When the single-surgeon learning curve cases were excluded from the analysis, the hospital mortality was $0.5 \%$ $(1 / 221)$ for single-vessel TECAB and $0.0 \%(0 / 45)$ for double-vessel TECAB $(P=.831)$ and the mortality was less than predicted using both the Society of Thoracic Surgeons risk score and the European System for Cardiac Operative Risk Evaluation.

The ventilation time was 2 hours longer for double-vessel TECAB, and a trend toward an increased rate of postoperative pulmonary infections was noted in patients undergoing double-vessel TECAB. With double-vessel TECAB, patients required, on average, $2 \mathrm{U}$ of blood compared with the $1 \mathrm{U}$ needed perioperatively with single-vessel TECAB. No significant difference was seen in the hospital length of stay. Patients in both groups had a quick return to normal activities, and no differences were seen between patients after single- and double-vessel TECAB with respect to this endpoint.

The 5-year survival was $93.9 \%$ after single-vessel TECAB and $95.8 \%$ after double-vessel TECAB $(P=.708$; Figure 1$)$. Freedom from angina showed a trend in favor of single-vessel TECAB, but the difference was not statistically significant (Figure 2). The freedom from major adverse cardiac and cerebral events at 5 years was approximately $10 \%$ lower after double-vessel TECAB (Figure 3). However, this difference also did not reach statistical significance.

\section{DISCUSSION}

Our series of 150 double-vessel TECAB operations has demonstrated that increasingly complex endoscopic

TABLE 3. Intraoperative results

\begin{tabular}{lccc}
\hline \multicolumn{1}{c}{ Variable } & $\begin{array}{c}\text { Single-vessel } \\
\text { TECAB }\end{array}$ & $\begin{array}{c}\text { Double-vessel } \\
\text { TECAB }\end{array}$ & $\begin{array}{c}\boldsymbol{P} \\
\text { value }\end{array}$ \\
\hline $\begin{array}{l}\text { Patients (n) } \\
\text { Conversion to larger } \\
\text { thoracic incision }\end{array}$ & 334 & 150 & \\
Any intraoperative & $31(9.3 \%)$ & $31(20.7 \%)$ & .001 \\
$\quad$ technical problem & $110(32.9 \%)$ & $66(44.0 \%)$ & .019 \\
Operative time (min) & & & \\
$\quad$ Including angiography & $285(112-690)$ & $402(183-1050)$ & $<.001$ \\
$\quad$ Surgery & $240(112-650)$ & $375(168-795)$ & $<.001$ \\
Aortic dissection & $3(0.9 \%)$ & $1(0.7 \%)$ & .634 \\
Upper/lower extremity ischemia & $2(0.6 \%)$ & $1(0.7 \%)$ & .602 \\
\hline
\end{tabular}

Data presented as $\mathrm{n}(\%)$ or median (range). TECAB, Total endoscopic coronary artery bypass grafting.
TABLE 4. Postoperative results

\begin{tabular}{|c|c|c|c|}
\hline Variable & $\begin{array}{c}\text { Single-vessel } \\
\text { TECAB }\end{array}$ & $\begin{array}{c}\text { Double-vessel } \\
\text { TECAB }\end{array}$ & $P$ value \\
\hline Patients (n) & 334 & 150 & \\
\hline Revision for bleeding & $21(6.3 \%)$ & $7(4.7 \%)$ & .317 \\
\hline Packed red blood cells & $1(0-28)$ & $2(0-27)$ & .002 \\
\hline Intra-aortic balloon pump & $4(1.2 \%)$ & $2(1.3 \%)$ & .602 \\
\hline Atrial fibrillation & $50(15.0 \%)$ & $21(13.8 \%)$ & .336 \\
\hline Ventilation time (h) & $8(0-278)$ & $10(0-288)$ & .006 \\
\hline Pneumonia & $10(3.0 \%)$ & $10(6.7 \%)$ & .055 \\
\hline Venoarterial ECMO & $0(0.0 \%)$ & $1(0.7 \%)$ & .310 \\
\hline CVVH & $3(0.9 \%)$ & $4(2.7 \%)$ & .138 \\
\hline Transitory ischemic attack & $0(0.0 \%)$ & $2(1.3 \%)$ & .096 \\
\hline Stroke & $6(1.8 \%)$ & $1(0.7 \%)$ & .307 \\
\hline Intensive care unit stay (h) & $21(11-389)$ & $39(12-480)$ & .047 \\
\hline Hospital stay (d) & $6(2-33)$ & $6(2-27)$ & .846 \\
\hline Hospital mortality & $1(0.3 \%)$ & $3(2.0 \%)$ & .091 \\
\hline \multicolumn{4}{|l|}{$\begin{array}{l}\text { Observed/expected } \\
\text { mortality ratio }\end{array}$} \\
\hline EuroSCORE & 0.15 & 1.00 & \\
\hline STS risk score & 0.51 & 3.51 & \\
\hline \multicolumn{4}{|l|}{ Interval to activities (d) } \\
\hline Walking outside & $7(3-180)$ & $7(3-90)$ & .556 \\
\hline Household work & $17(4-360)$ & $17(7-120)$ & .205 \\
\hline Driving & $21(5-90)$ & $21(5-60)$ & .372 \\
\hline Full activity, including sports & $50(10-365)$ & $44(7-720)$ & .954 \\
\hline
\end{tabular}

Data presented as n (\%) or median (range). TECAB, Total endoscopic coronary artery bypass grafting; $E C M O$, extracorporeal membrane oxygenation; $C V V H$, continuous venovenous hemofiltration; EuroSCORE, European System for Cardiac Operative Risk Evaluation; STS, Society of Thoracic Surgeons.

coronary artery bypass surgery is feasible and reproducible. Compared with single-vessel TECAB, the procedure appears technically more demanding, as reflected by the longer operative times and greater conversion rate. Additionally, this complexity results in postoperative morbidity, such as increased blood transfusion requirements and greater ventilation times. However, the hospital stay was similar and patients recovered equally quickly after singleand double-vessel TECAB. No difference was seen in longterm outcomes, and we found only a slight trend favoring single-vessel TECAB with respect to freedom from symptoms and major adverse cardiac and cerebral events.

\section{Patient Selection}

We chose a relatively low-risk cohort with a predicted mortality of $2 \%$ according to the European System for Cardiac Operative Risk Evaluation and a predicted mortality of $0.5 \%$ according to Society of Thoracic Surgeons risk score. Patients undergoing double-vessel TECAB had had previous myocardial infarcts more frequently and had a greater incidence of cerebrovascular disease than did patients undergoing single-vessel TECAB. Patients requiring dialysis underwent only single-vessel TECAB to avoid long, complex procedures in this specific risk group. Also, only 1 


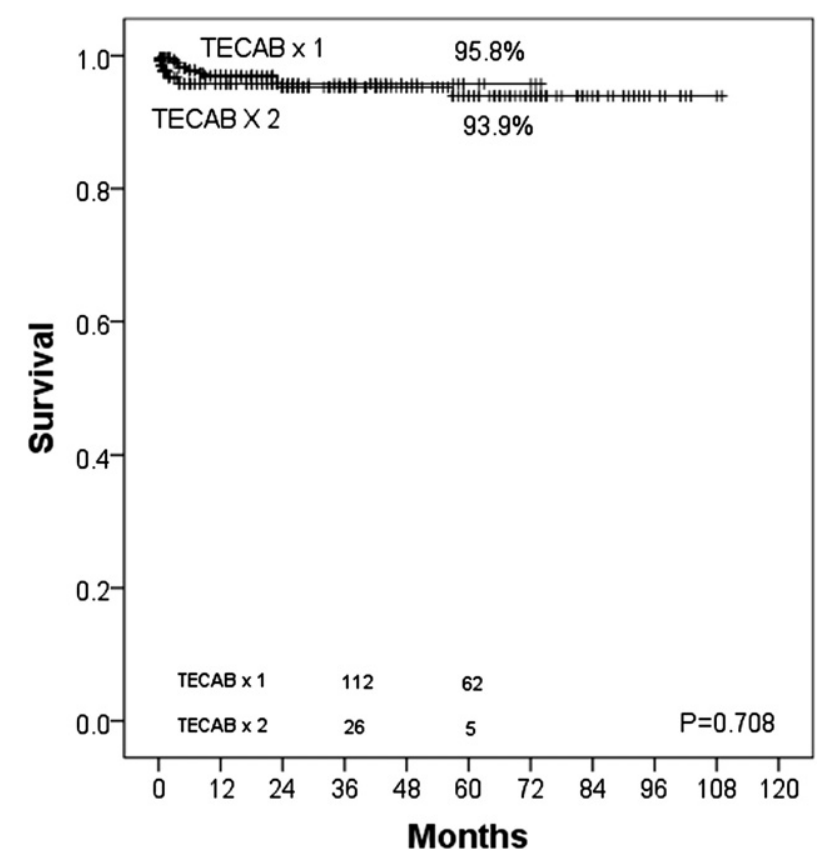

FIGURE 1. Cumulative survival in patients after single- and doublevessel total endoscopic coronary artery bypass grafting (TECAB).

of 3 operations in the single-vessel group was a learning curve case, but $70 \%$ of the double-vessel cases were within a single surgeon's learning curve. The perioperative mortality was $0 \%$ and $0.5 \%$ for single- and double-vessel TECAB, respectively, after these learning curves were overcome.

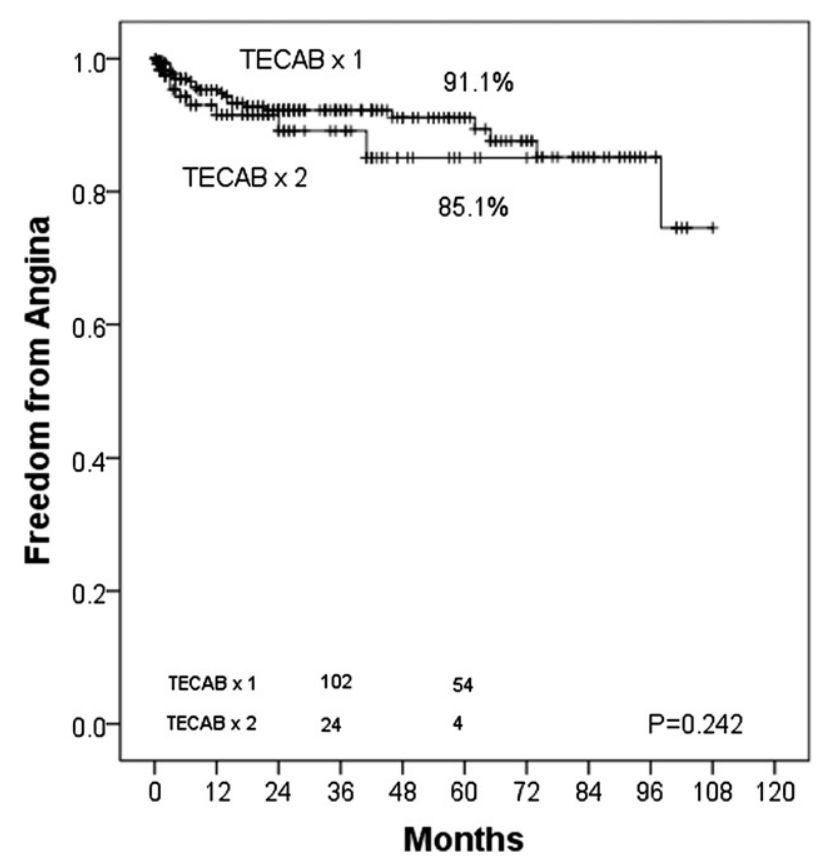

FIGURE 2. Cumulative freedom from angina in patients after single- and double-vessel total endoscopic coronary artery bypass grafting (TECAB).

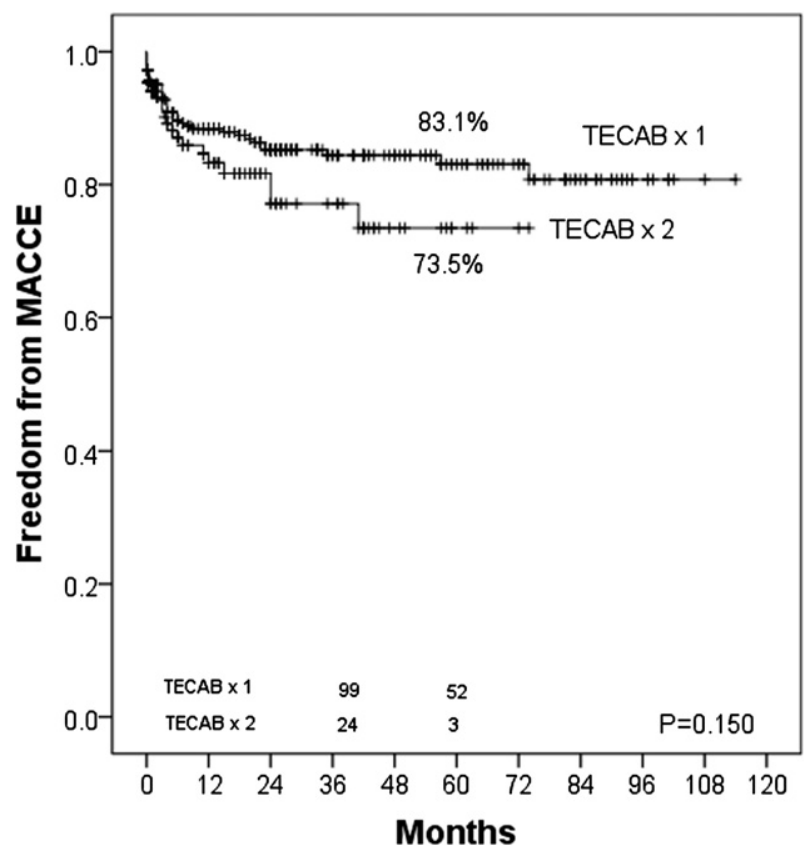

FIGURE 3. Cumulative freedom from major adverse cardiac and cerebral events $(M A C C E)$ in patients after single- and double-vessel total endoscopic coronary artery bypass grafting (TECAB).

\section{Operative Technique}

The present series has demonstrated that a variety of total endoscopic coronary artery bypass grafting (CABG) procedures can be performed. Both arterial and venous grafts can be used, and beating heart and arrested heart approaches are feasible. The first double-vessel TECAB was reported by Kappert and colleagues ${ }^{1}$ in 2000, in which a right ITA to the left anterior descending artery and left ITA to the obtuse marginal branch were placed using an arrested heart technique. The beating heart version of this procedure was first described in $2004 .^{2}$

We performed our initial double-vessel TECABs using the arrested heart technique, because we believed a completely unloaded and flaccid heart would better facilitate rotation and access to the side and back walls of the heart. We described a specific exposure technique for accessing the circumflex coronary artery system in $2006 .^{7}$ In select beating heart cases, exposure of the side and back walls of the heart was enhanced by unloading the left ventricle "on pump." 6,8

Our study has also demonstrated that sequential or socalled jump grafts can be performed reproducibly in the closed chest. The group from Frankfurt, Germany introduced this sequential endoscopic bypass grafting technique in 2002 and published a preliminary series. ${ }^{9}$ We also showed that Y-grafts have become a part of the armamentarium of robotic endoscopic coronary surgeons. Balkhy and colleagues, ${ }^{10}$ in their recent series of 120 patients undergoing TECAB using automated anastomotic connectors, also 
performed sequential grafts and Y-graft constructs. Because the performance of aortocoronary bypass grafts is difficult in the completely endoscopic setting, we regard the development of sequential and Y-grafts as a major step in procedure development.

\section{Operative Times and Conversion Rates}

Our data have revealed that double-vessel TECAB has significantly increased operative time requirements compared with single-vessel procedures. The double-vessel operative time was about 6 hours; however, ideal cases can be performed in only 4 hours. Few data are available regarding the time requirements for double-vessel TECAB performed by other groups. Dogan and colleagues ${ }^{9}$ reported an operative time of 7 hours for sequential left ITA to left anterior descending artery and diagonal branch bypasses during a learning curve period. The earliest TECAB reports on double-ITA grafting reported an operative time of 6 hours for arrested heart and 5.5 hours for beating heart procedures. $^{1,2}$ In their 2010 report, Srivastava and colleagues ${ }^{11}$ reported a time of 5 hours, 20 minutes for double-vessel beating heart TECAB and approximately 3 hours for single-vessel procedures.

Because of the complexity of double-vessel TECAB operations, a greater rate of conversion to a larger thoracic incision was expected when we started our program. Significant conversation rates have been reported in other intricate robotic procedures, such as Whipple operations and endoscopic cystectomy for bladder cancer. ${ }^{12,13}$ Our conversion rate of $20.7 \%$ for double-vessel TECAB was comparable to the conversion rates described in early single-vessel TECAB series, which were in the $20 \%$ range. ${ }^{9,14,15}$ A decrease in the conversion rate to about 5\% has been described for single-vessel TECAB as one progresses beyond the learning curve, ${ }^{6}$ and we expect to see this decrease with double-vessel TECAB as well.

\section{Postoperative Course}

More postoperative clinical events occurred after doublevessel TECAB than after single-vessel TECAB. However, our first 150 double-vessel TECAB cases represented our early experience and $70 \%$ of the cases were within the learning curve. In contrast, one third of our single-vessel TECABs were learning curve cases. Dogan and colleagues, ${ }^{9}$ in 2002, also reported longer intensive care unit and hospital stays for patients undergoing total endoscopic left anterior descending artery and diagonal branch sequential grafts. This too, however, was a very early learning curve experience.

We chose a threshold of 20 cases to define our learning curve. From our experience, both the time needed to complete a specific procedural task (eg, ITA harvesting, anastomotic suturing) and the total operative time began to improve significantly after the first 20 cases. Nevertheless, a triple digit number of cases is likely needed to achieve a steady state in terms of consistent task-specific and total operative times. Moreover, only with this many cases, can one attain a high level of comfort.

Morbidity after double-vessel TECAB mainly affected the respiratory system. Prolonged periods of single-lung ventilation most likely contributed significantly to this finding. Patients undergoing double-vessel TECAB received, on average, $2 \mathrm{U}$ of blood perioperatively. We have recently illustrated that the causes for blood transfusions after arrested heart TECAB are multifactorial. ${ }^{16}$ It can be anticipated that with additional technical improvements, the blood transfusion requirements in double-vessel TECAB will likely decrease. An additional contributor to morbidity with double-vessel TECAB is addressed by our recent finding that a clear correlation exists between the operative times and conversion to a larger incision. ${ }^{16}$ Hence, improving operative times and avoiding the technical problems that lead to these conversions will be imperative in decreasing perioperative morbidity as we move forward.

Concerning mortality, our results did seem to meet the current quality standards, because they were in line with the mortality rates reported in contemporary studies. For example, in their series of 68 double-vessel and 139 singlevessel TECABs, Srivastava and colleagues ${ }^{11}$ observed no mortalities in nonconverted cases. Balkhy and colleagues, ${ }^{10}$ in a mixed series of single- and double-vessel TECABs, reported an overall 30 -day mortality of $0.8 \%$. Risk scores were unavailable from either study, however, and in the latter study, 10 very early learning curve cases were excluded. A significant decrease in mortality was observed in our present series after the initial learning curve had been overcome.

\section{Early Rehabilitation Phase}

Our data have shown that after both single- and doublevessel TECAB, patients are able to return to their normal activities more quickly than those undergoing traditional coronary bypass surgery through sternotomy. Patients returned to full activity levels-including sports-within 6 to 7 weeks, far shorter than the 10 -week period of sternal precautions usually recommended after standard CABG. Kon and colleagues ${ }^{17}$ previously demonstrated similar findings after robotically assisted coronary bypass surgery through minithoracotomy. Our Innsbruck team has also shown that after TECAB, patients have advantages with respect to postoperative rehabilitation compared with those who underwent sternotomy and those converted to sternotomy. ${ }^{18}$ We believe these quality of life data justify the investment of longer operative times and the technical challenges of robotic surgery.

\section{Intermediate-Term Results}

Currently, no published data are available on the intermediate- or long-term results after multivessel TECAB. Our 
double-vessel TECABs resulted in the same 5-year survival as was observed for our single-vessel procedures. Moreover, our intermediate-term results have demonstrated that our freedom from angina and freedom from major adverse cardiac and cerebral events were comparable to the results seen after open CABG reported in classic comparative trials such as the Arterial Revascularization Therapies Study, thereby further demonstrating that multivessel robotic interventions are safe in the intermediate term. ${ }^{19}$

\section{CONCLUSIONS}

Having performed 150 double-vessel TECAB procedures, this operation appears to be reproducible and safe. The technical performance and perioperative results, at present, are slightly inferior to the postlearning curve results for single-vessel TECAB. However, the intermediate-term freedom from symptoms and freedom from adverse events seem to be comparable to the results seen for single-vessel TECAB and meet the standards of open CABG using the traditional sternotomy approach. The learning curve effects are visible.

\section{References}

1. Kappert U, Cichon R, Schneider J, Schramm I, Schüler S. Closed chest bilateral mammary artery grafting in double-vessel coronary artery disease. Ann Thorac Surg. 2000;70:1699-701.

2. Farhat F, Aubert S, Blanc P, Jegaden O. Totally endoscopic off-pump bilateral internal thoracic artery bypass grafting. Eur J Cardiothorac Surg. 2004;26: 845-7.

3. Bonatti J, Schachner T, Bonaros N, Ohlinger A, Rutzler E, Feuchtner G, et al Robotic totally endoscopic double-vessel bypass grafting: a further step toward closed-chest surgical treatment of multivessel coronary artery disease. Heart Surg Forum. 2007; 10:E239-42.

4. Bonatti J, Schachner T, Bonaros N, Lehr E, Zimrin D, Griffith B. Robotic assisted endoscopic coronary bypass surgery. Circulation. 2011;124:236-44.

5. Srivastava S, Gadaselli S, Agusalla M, Kolluru R, Barrera R, Quismundo S, et al. Beating heart totally endoscopic coronary artery bypass. Ann Thorac Surg. 2010; 89:1873-80.
6. Bonatti J, Garcia J, Rehman A, Odonkor P, Haque R, Zimrin D, et al. On-pump beating-heart with axillary artery perfusion: as solution for robotic totally endoscopic coronary artery bypass grafting? Heart Surg Forum. 2009;12:E131-3.

7. Bonatti J, Schachner T, Bonaros N, Laufer G. A new exposure technique for the circumflex coronary artery system in robotic totally endoscopic coronary artery bypass grafting. Interact Cardiovasc Thorac Surg. 2006;5:279-81.

8. Lehr EJ, Odonkor P, Reyes P, Bonatti J. Minimized extracorporeal circulation for the robotic totally endoscopic coronary artery bypass grafting hybrid procedure. Can J Cardiol. 2010;26:e286-7.

9. Dogan S, Aybek T, Andressen E, Byhahn C, Mierdl S, Westphal K, et al. Totally endoscopic coronary artery bypass grafting on cardiopulmonary bypass with robotically enhanced telemanipulation: report of forty-five cases. J Thorac Cardiovasc Surg. 2002;123:1125-31.

10. Balkhy H, Wann S, Krienbring D, Arnsdorf S. Integrating coronary anastomotic connectors and robotics toward a totally endoscopic beating heart approach: review of 120 cases. Ann Thorac Surg. 2011;92:821-8.

11. Srivastava S, Gadasalli S, Agusala M, Kolluru R, Barrera R, Quismundo S, et al. Beating heart totally endoscopic coronary artery bypass. Ann Thorac Surg. 2010; 89:1873-80.

12. Giulianotti P, Coratti A, Angelini M, Sbrana F, Cecconi S, Balestracci T, et al. Robotics in general surgery: personal experience in a large community hospital. Arch Surg. 2003;138:777-84.

13. Schumacher MC, Jonsson MN, Wiklund NP. Robotic cystectomy. Scand J Surg. 2009;98:89-95

14. Falk V, Diegeler A, Walther T, Banusch J, Brucerius J, Raumans J, et al. Total endoscopic computer enhanced coronary artery bypass grafting. Eur J Cardiothorac Surg. 2000;17:38-45.

15. de Canniere D, Wimmer-Greinecker G, Cichon R, Gulielmos V, Van Praet F, Seshadri-Kreaden U, et al. Feasibility, safety, and efficacy of totally endoscopic coronary artery bypass grafting: multicenter European experience. J Thorac Cardiovasc Surg. 2007;134:710-6.

16. Bonatti J, Schachner T, Bonaros N, Oehlinger A, Wiedemann D, Weidinger F, et al. Factors influencing blood transfusion requirements in robotic totally endoscopic coronary artery bypass grafting on the arrested heart. Eur J Cardiothorac Surg. 2011;39:262-7.

17. Kon ZN, Brown EN, Tran R, Joshi A, Reicher B, Grant MC, et al. Simultaneous hybrid coronary revascularization reduces postoperative morbidity compared with results from conventional off-pump coronary artery bypass. $J$ Thorac Cardiovasc Surg. 2008;135:367-75.

18. Bonaros N, Schachner T, Wiedemann D, Oehlinger A, Ruetzler E, Feuchtner G, et al. Quality of life improvement after robotically assisted coronary artery bypass grafting. Cardiology. 2009;114:59-66.

19. Serruys PW, Ong ATL, van Herwerden LA, Sousa JE, Jatene A, Bonnier JJRM, et al. Five-year outcomes after coronary stenting versus bypass surgery for the treatment of multivessel disease: the final analysis of the Arterial Revascularization Therapies Study (ARTS) randomized trial. J Am Coll Cardiol. 2005;46: $575-81$ 